\title{
Influence of Earthquake Rotational Components on the Seismic Safety of Steel Structures
}

\author{
Nikos Pnevmatikos ${ }^{1}(0)$, Foteini Konstandakopoulou ${ }^{2}$, , George Papagiannopoulos ${ }^{2}$ (), \\ George Hatzigeorgiou ${ }^{2, *(\mathbb{D})}$ and Georgios Papavasileiou ${ }^{3}$ \\ 1 Department of Civil Engineering, School of mechanics, University of West Attica, 12241 Athens, Greece; \\ pnevma@uniwa.gr \\ 2 School of Science and Technology, Hellenic Open University, 25335 Patras, Greece; \\ konstantakopoulou.foteini@ac.eap.gr (F.K.); papagiannopoulos.georgios@ac.eap.gr (G.P.) \\ 3 School of Construction and the Built Environment, University of the Highlands and Islands, \\ Inverness IV25NA, UK; georgios.papavasileiou.ic@uhi.ac.uk \\ * Correspondence: hatzigeorgiou@eap.gr; Tel.: +30-2610-367-769
}

Received: 23 January 2020; Accepted: 27 February 2020; Published: 5 March 2020

check for updates

\begin{abstract}
In this work a seismic analysis of structure associated with the complete description of ground motion components is performed. All earthquake excitation components corresponding to the six degrees of freedom, translational and rotational ones need to be taken into account for a realistic simulation of structural performance. The impact of the rotational components of an earthquake to the overall response of a steel structure is examined. Typically, in response to the history analyses, the seismic input is descripted by its translational component only, while the rotational components are ignored. This is because the rotational component requires special devices to be recorded in adequate detail. This is one of the reasons why this component is often ignored. With the currently available technology, such an instrument can be constructed and provide detailed records that can be used for the response history analysis of structures. The applicable design codes using a simplified response spectrum analysis accounting for rotational components is proposed and elastic design response spectra are introduced. Another reason why the rotational component was not taken into account in structural analysis is that it does not have significant effect on low-rise buildings. In this work, the analysis results in terms of response and internal forces when accounting for the rotational component is demonstrated. A case study on the response history analysis of symmetrical and non-symmetrical steel structures subjected to earthquake excitation with and without the rotational component of the excitation was performed. Numerical results show that the influence of the rotational component on the structural behaviour is important and should be taken into account in the design process.
\end{abstract}

Keywords: rotational components; seismic design; seismic safety; earthquake engineering; steel structure; EC8 part 6; vibrations

\section{Introduction}

A detailed response history analysis of a structure requires a full description of the earthquake excitation, using all its components in a three-dimensional space. To achieve that, both the translational and rotational components of the earthquake excitation should be applied at the base of the structure. Limited capabilities of sensor devices, as well as the assumption that it does not affect significantly the structural behaviour, based on observations on low-rise buildings, leads to a lack of use of this component in earthquake simulations. The recording of rotational components can take place in a free field using special accelerometers or it can be extracted from the translational recordings. 
Many researchers in the fields of earthquake engineering and seismology focused on the rotational component recordings over the past decades. Droste and Teisseyre [1] using the signals taken from an array of seismographs calculated the rotational components of the excitations. Takeo [2] using a gyro-sensor with combination of inertial angular displacement sensor measured the rotational motion during a series of earthquakes that took place in April 1998 in Japan. Advances in rotational seismology about instrumentation, theory and observations are presented in the work of Igel et al. [3]. Affordable sensors based on electrochemical magnetohydrodynamic technology were used by Liu et al. [4] and Wassermann et al. [5]. There are various procedures that derive the rotational time series from translational recordings. A Single Station Procedure (SSP), is one of them. A number of researchers, such as Lee and Trifunac, [6], Castellani and Boffi [7], Li et al. [8] and Basu et al. [9], presented their work based on SSP. An extension to the SSP method is the use of data from a number of closely spaced, spatially distributed stations, this procedure is called Multiple Station Procedures, denoted as MSP, Niazi [10]. An expansion of MSP is the Geodetic Method (GM) used by Spudich et al. [11,12]. To overcome the limitations of GM, Basu et al. [13] suggested a similar method, i.e., the Acceleration Gradient Method (AGM). With the AGM, using a dense array of sensors, it is possible to obtain the rotational motions from the three-translational components which are recorded at surface stations. However, the above method is not capable of extracting the frequency content above a frequency limit. This frequency limit is reduced as the physical dimension of the array is increasing. The shortcoming of AGM is overcome using another similar method called Surface Distribution Method (SDM), proposed by Basu et al. [14].

Falamarz-Sheikhabadi et al. [15,16] worked on the effects of both time-delay and loss of coherency in order to derive simple mathematical expressions for generating the middle-field rocking acceleration component and its corresponding response spectra. They revised the seismic intensity parameters in order to account for the combined action of horizontal and rocking seismic motion on structures. Sbaa et al. [17] and Perron et al. [18] indicate that site soil conditions are related to the rotational component of earthquake excitations. They show that the interaction between translation and rotation records can be utilised for engineering seismological applications and investigation of the composition of the wavefield, so that the deployment of dense arrays can be avoided.

The need to consider the rotational components is also pointed out in the design regulations. EN1998-6, [19], that focuses on the design of slender and tall structures such as towers, chimneys and masts, takes into account the special variability of the seismic ground motion including rotational components of the ground accelerations. It proposes an extended response spectrum analysis which requires response spectra of rotational accelerations to be implemented. Such rotational spectra are defined and calculated on the basis of translational response spectra as well.

Various works in literature investigate the effect of the rotational component of ground motion on structural response of base-isolated structures. The influence of the rotational component on a base-isolated nuclear power plant was investigated by Wolf et al. [20]. Another application of rotational excitation in a base-isolated building and the rocking mode identification was done by Politopoulos, [21]. Bozev et al. [22], performed analysis accounting for the rotational component of seismic action on towers, masts and chimneys according to EN1998-6. Zembaty, [23], worked on rotational seismic code definition in EN1998-6, for slender tower-shaped structures. Zembaty and Boffi [24] apply response spectrum analysis using horizontal and rotational spectra described in EN1998 and show the effect of the rotational excitation to moments diagram along the height of a tall tower. In a recent work, [25], the rotational ground-motion records from induced seismic events are examined. A simplified relation for the application of rotational components to seismic design codes and calculation of response of multiple-support structures subjected to horizontal and rocking components are presented in the work [26,27]. Basu et al. [28] suggested an equivalent accidental eccentricity to account for the effects of torsional ground motion on structures. Torsion in building due to base rotational excitation was investigated by De-La-Llera and Chopra, [29]. Yin et al. performed earthquake time-history analysis 
using recorded rotation ground excitation on a structure, [30]. Pnevmatikos et al. [31,32] investigated the effect of the rotational components of seismic excitations on steel slender structures.

This work shows the effect of rotation ground motion component to the structural response of steel buildings. The response is calculated solving directly the equations of motions accounting for the rotational component applied at the base of structure. Directly response history geometrical non-linear analysis is performed in order to calculate the response of the structures.

\section{Theoretical Background}

The rotational components of an earthquake excitation consist of one torsional component, which is the rotation about the vertical axis and two rocking components, which are the rotation about the two horizontal axes. The secondary horizontal wave, SH wave, and the surface wave, Love wave, contribute to the torsional motion. Rocking motion is due to the primary waves, $\mathrm{P}$ waves, secondary vertical waves, SV waves, and Rayleigh waves. Even though that rotational components of an earthquake ground motion have been studied in literature, in seismic analysis and design of structures they are not taken into account, mainly because such data were not recorded by typical accelerographs. In EN1998-6, the rotational components of the ground accelerations need to be taken into account during seismic analysis. Response spectrum analysis or direct response history analysis can be used to evaluate the response of structure subjected to rotational component. The response spectrum analysis requires response spectra of rotational accelerations to be implemented. In EN1998-6, rotational spectra are defined in order to use in the analysis. Response history analysis requires rotational ground motion records to be applied on the base of slender and tall structures such as towers, chimneys and masts. These structures are specially mentioned in EN1998-6. However, other structures such as long-in-plan structures, bridges, dams, high-rise buildings or special buildings such as nuclear power stations, which are also expected to be influenced by the rotational components of seismic action, are not explicitly considered.

In earthquake engineering literature, the terms 'ground acceleration' and 'velocity' are often related to the translational component of acceleration and velocity only. Terms such as 'translational acceleration' and 'translational velocity' need to be used to distinguish these components from the rotational acceleration and rotational velocity respectively. The term 'rotational rate' instant of rotational velocity is also often used in the rotational seismology literature. Thus, Peak Ground Translational Acceleration (PGTA) instead of Peak Ground Acceleration (PGA) and Peak Ground Rotational Acceleration (PGRA) are defined as the maximum absolute acceleration values of all three translational and three rotational components respectively.

The total translational displacement due to the rotational and translational components of the earthquake excitation of a single-degree-of-freedom (SDOF) system is shown in Figure 1.

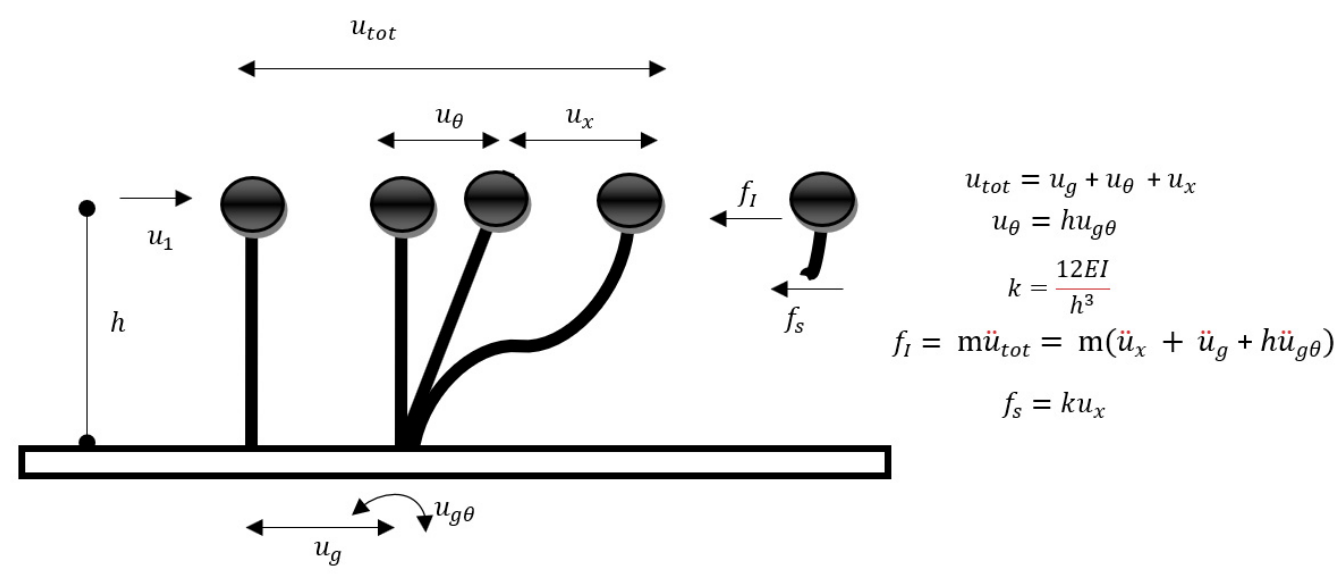

Figure 1. Total translational displacement due to the rotational and translational components of the earthquake excitation of a single-degree-of-freedom (SDOF) system. 
Applying the theory presented in work of Chopra [33] a dynamic equilibrium to SDOF, the equation of motion is obtained as follows:

$$
\mathrm{m} \ddot{u}_{x}+\mathrm{c} \dot{u}_{x}+\mathrm{k} u_{x}=-\left(m \ddot{u}_{g}+m h \ddot{u}_{g \theta}\right)
$$

Considering two degrees of freedom for the mass, one translational and one rotational, and ignoring the damping, the system is subjected again to the translational and rotational components of the earthquake excitation. The total displacement of the mass is shown in Figure 2. Appling the force and moment equilibrium, the corresponding equations of motion are obtained, Equation (2). In matrix form they can be expressed as shown in Equation (3).

$$
\begin{gathered}
f_{I}+f_{s}=0 \Leftrightarrow m \ddot{u}_{x}+\frac{12 E I}{h^{3}} u_{x}+\frac{6 E I}{h^{2}} \theta=-\left(m \ddot{u}_{g}+m h \ddot{u}_{g \theta}\right) \\
M_{I}+M_{s}=0 \Leftrightarrow I_{c m} \ddot{\theta}+\frac{6 E I}{h^{2}} u_{x}+\frac{4 E I}{h} \theta=-I_{o} \ddot{u}_{g \theta} \\
{\left[\begin{array}{cc}
m & 0 \\
0 & I_{c m}
\end{array}\right]\left\{\begin{array}{c}
\ddot{u}_{x} \\
\ddot{\theta}
\end{array}\right\}+\left[\begin{array}{cc}
\frac{m \frac{12 E I}{h^{3}}}{\frac{6 E I}{h^{2}}} \\
\frac{6 E I}{h^{2}} & \frac{4 E I}{h}
\end{array}\right]\left\{\begin{array}{c}
u_{x} \\
\theta
\end{array}\right\}=\left[\begin{array}{cc}
m & m h \\
0 & I_{o}
\end{array}\right]\left\{\begin{array}{c}
\ddot{u}_{g} \\
\ddot{u}_{g \theta}
\end{array}\right\}}
\end{gathered}
$$
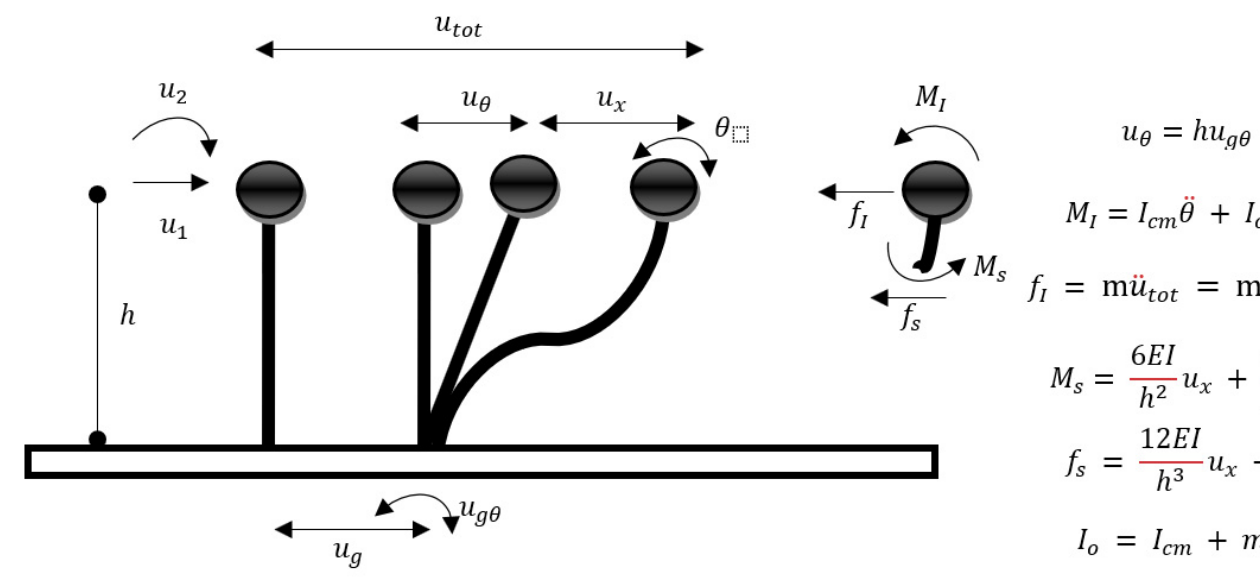

$$
\begin{gathered}
M_{I}=I_{c m} \ddot{\theta}+I_{o} \ddot{u}_{g \theta} \\
f_{I}=m \ddot{u}_{t o t}=\mathrm{m}\left(\ddot{u}_{x}+\ddot{u}_{g}+h \ddot{u}_{g \theta}\right) \\
M_{s}=\frac{6 E I}{h^{2}} u_{x}+\frac{4 E I}{h^{5}} \theta \\
f_{s}=\frac{12 E I}{h^{3}} u_{x}+\frac{6 E I}{h^{2}} \theta \\
I_{o}=I_{c m}+m h^{2}
\end{gathered}
$$

Figure 2. Total translational displacement due to the rotational and translational components of the earthquake excitation of a two-degree-of-freedom system.

A model of the structure with concentrated mass and stiffness at each floor considering the horizontal degrees of freedom and ignoring the rotation of slabs, subjected to ground motion with translational and rotational components is shown in Figure 3.

If $(M)$ is the mass matrix, $(K)$ is the stiffness matrix and $(C)$ is the damping matrix, the equation of motion for structure considering a translational ground acceleration along horizontal direction $x$ together with a rotation acceleration in the vertical plane $\mathrm{x}-\mathrm{z}$ are given by:

$$
[M]\{\ddot{u}\}+[C]\{\dot{u}\}+[K]\{u\}=-(\{m\} \ddot{x}+\{m h\} \ddot{\theta})
$$

$\{\ddot{\mu}\}$ : is the vector comprising the accelerations of the degrees of freedom of the structure relative to the base,

$\{\mu\}$ : is the vector comprising the velocities of the degrees of freedom of the structure,

$\{\mu\}$ : is the vector comprising the displacements of the degrees of freedom relative to the base,

$\{m\}$ : is the vector comprising the translational masses in the horizontal direction of the translational excitation. This vector coincides with the main diagonal of the mass matrix (M), if the vector $\{u\}$ includes only the translational displacements in the horizontal direction of the excitation,

$\ddot{x}_{\mathrm{g}}(t)$ : is the translational ground acceleration,

$\ddot{\theta}_{\mathrm{g}}(t)$ :is the rotational acceleration at the base. 

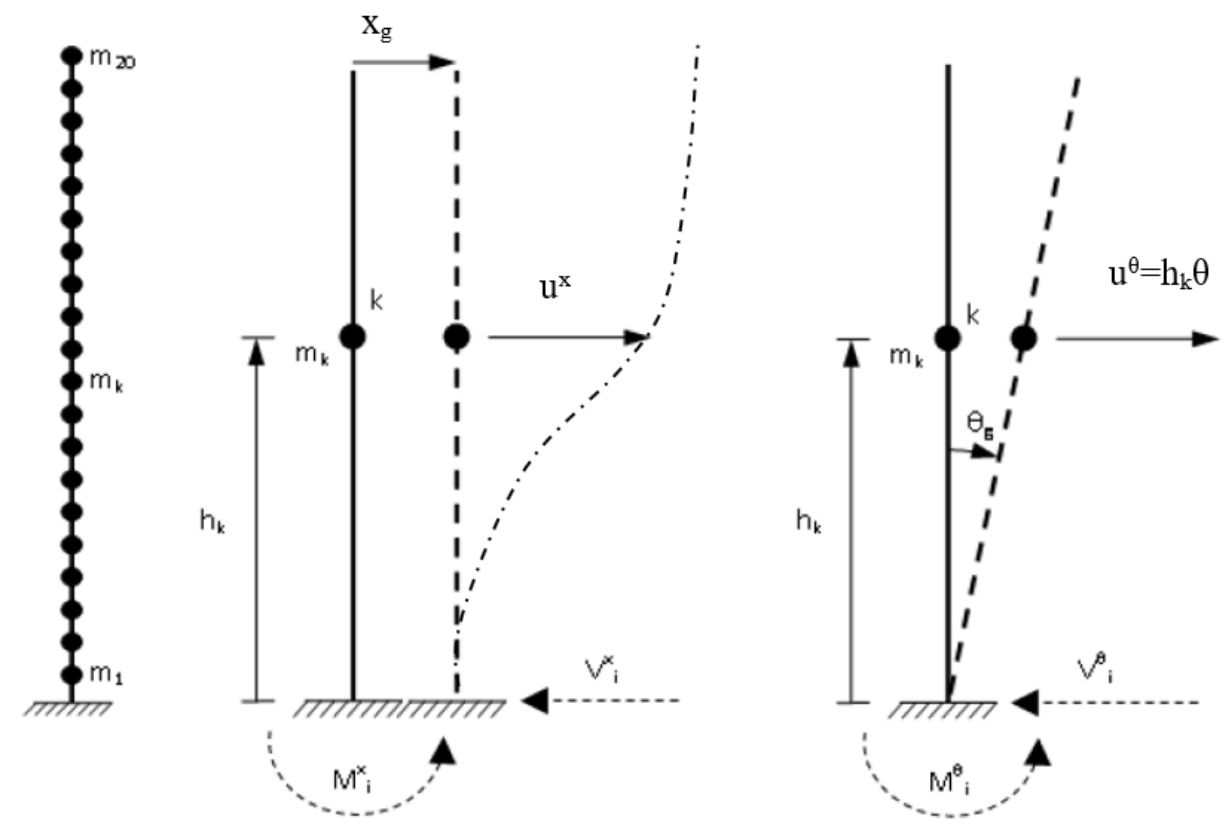

Figure 3. Response of a concentrated mass and stiffness model subjected to ground motion with translational and rotational components.

The above equation can be extended to three dimensions. In that case, the excitation motion consists of three translational accelerations, two rotational accelerations (rotation about the two horizontal axes, i.e., rocking) and one torsional acceleration (rotation about the vertical axis).

Response history analysis can be used to calculate the response of structure subjected to translational and rotational component of ground motion. With this analysis, the response is calculated solving directly with a numerical procedure the above equation (Equation (3)). Response (history analysis can be linear or non-linear. Non-linearity can be due to material (change of stiffness matrix at every step) or due to geometry (solving the equation in deformable petition at each analysis step).

\section{Case Studies, Numerical Results and Discussion}

The influence of the rotational component of an earthquake has been numerically approached. Different plane and 3D models were subjected to an earthquake excitation with translational and rotational component. The models were: (a) a single-degree-of-freedom model, (b) a two-storey frame building and (c) a ten-storey frame building. The single-degree-of-freedom model has a fundamental period equal to the primary fundamental period $\left(\mathrm{T}_{1}\right)$ of the ten-storey frame. Two more three-dimensional models, a symmetrical ten-story and an irregular-floor-plan steel space frames were modelled. All models have a $3 \mathrm{~m}$ inter-storey height and $4 \mathrm{~m}$ bay spans. The loads considered, section sizes and layout of the models are shown in Figure 4.

All models were subjected to a 6.4 moment magnitude, Mw, earthquake excitation, which took place on 17/11/2015 in Kefalonia island, Greece. The epicentre latitude and longitude were $38.16^{\circ}$ and $20.50^{\circ}$, respectively. The focus of the earthquake was at $10.7 \mathrm{~km}$ below surface level. The record history of translational and rotational components were recorded in the framework of the Argonet project, a 3D accelerometric array implemented on the island of Kefalonia in Greece $[17,18]$, and is shown in Figure 5.

Elastic response history analysis was applied, using the SAP 2000 software package, [34], and the response of the structure was monitored. Two cases of earthquake excitation were considered: (a) one with application of the translational acceleration only at the base of structure and (b) one with simultaneous translational and rotational accelerations considered. In the three-dimensional structures, except for the above cases, a third case where all six components of the excitation (three translational and three rotational) were applied at the base of the structure was also simulated. 


\begin{tabular}{|l}
\hline Steel $\mathrm{S} 235$ \\
$\mathrm{~g}=36 \mathrm{kN} / \mathrm{m}$ \\
$\mathrm{q}=30 \mathrm{kN} / \mathrm{m}$
\end{tabular}

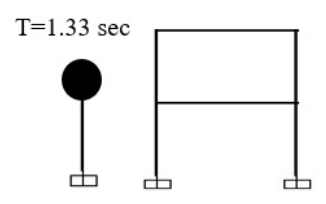

Figure 4. Properties, materials characteristics and geometry layout of the structural models assessed.

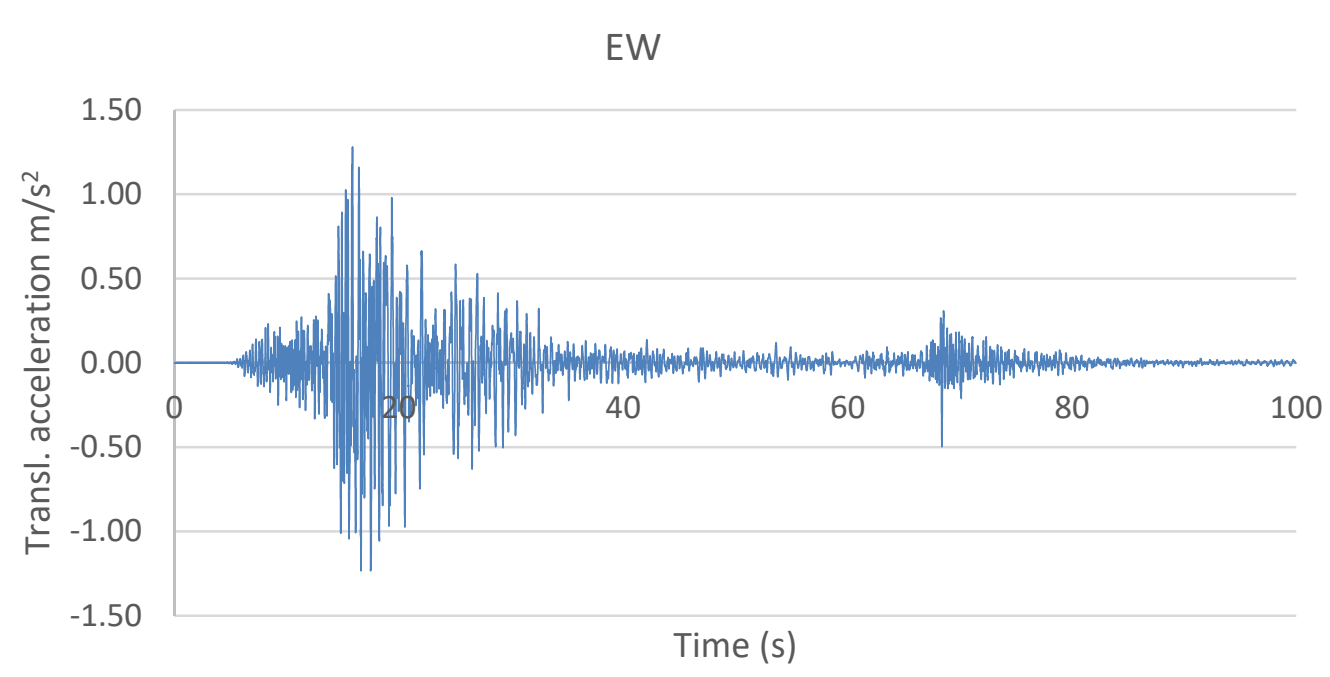

(a)

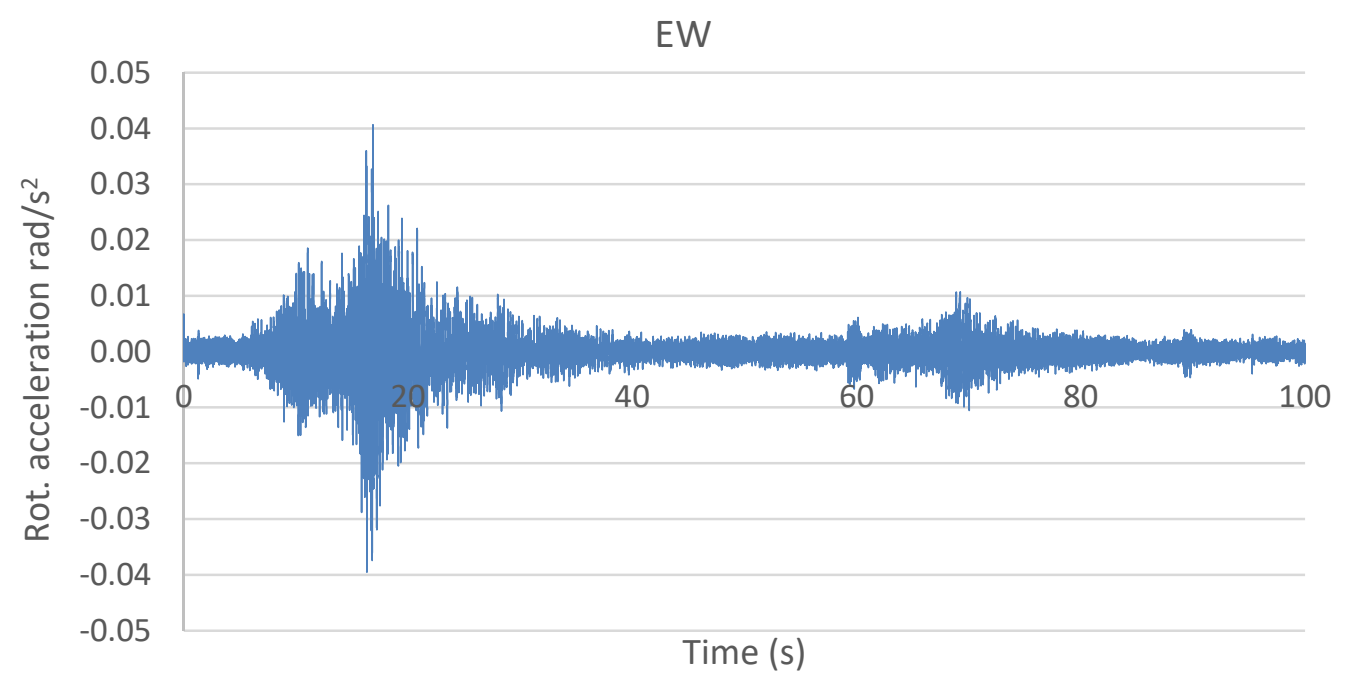

(b)

Figure 5. Two components: (a) translational and (b) rotational of earthquake excitation. 
The results of the analysis in terms of displacement, acceleration and base shear of each structure are shown in Table 1. In this table, the ratio of the response of the structure excited with translational and rotational acceleration, denoted as $\mathrm{T}+\mathrm{R}$, to the response of structure excited only with translational acceleration, denoted as $R$, is shown. The graphical representation of the Table 1 is shown in Figure 6.

From the analysis results, it is indicated that the top displacement, the acceleration and the base shear of structure subjected to rotational and translational component of earthquake are higher compared to the displacement, acceleration and base shear of the structure subjected only to translational excitation. The ratio of the response of the structure subjected to rotational and translational component of earthquake to the response of structure subjected only translational excitation, $(T+R) / T$ ranges from 1.1 to 1.6, depending on the type of building and response considered in the analysis. In Figure 6, it is clear that for any type of the response (displacement, acceleration or base shear), the ratio $(T+R) / T$ is greater than one, that is indicative of the effect of the rotational components on all structural models.

Table 1. Numerical values of ratio of response due to translational and rotational component to the response of only translational component, $(T+R) / R$.

\begin{tabular}{ccccc}
\hline Structural Model & Response & $\begin{array}{c}\text { Top Displacement } \\
\mathbf{( c m )}\end{array}$ & $\begin{array}{c}\text { Top Acceleration } \\
\left(\mathbf{m} / \mathbf{s e c}^{2}\right)\end{array}$ & $\begin{array}{c}\text { Base Shear } \\
(\mathbf{k N})\end{array}$ \\
\hline SDOF $(\mathrm{T}=1.5 \mathrm{sec})$ & 1.18 & 1.13 & 1.18 \\
\hline Two-storey plane frame & 1.05 & 1.14 & 1.05 \\
\hline $\begin{array}{c}\text { Ten-storey plane frame } \\
\left(\mathrm{T}_{1}=1.5 \mathrm{sec}\right)\end{array}$ & $\mathrm{EW}$ & 1.15 & 1.20 & 1.16 \\
\hline \multirow{2}{*}{$\begin{array}{c}\text { Ten-storey space frame, } \\
\text { regular }\end{array}$} & $\mathrm{NS}$ & 1.45 & 1.58 & 1.42 \\
\cline { 2 - 5 } & $\mathrm{ALL}(6 \mathrm{DOF})$ & 1.30 & 1.40 & 1.45 \\
\cline { 2 - 5 } & $\mathrm{EW}$ & 1.44 & 1.59 & 1.41 \\
\cline { 2 - 5 } $\begin{array}{c}\text { Ten-storey space frame, } \\
\text { irregular }\end{array}$ & $\mathrm{NS}$ & 1.24 & 1.39 & 1.36 \\
\cline { 2 - 5 } & $\mathrm{ALL}(6 \mathrm{DOF})$ & 1.39 & 1.56 & 1.48 \\
\hline
\end{tabular}

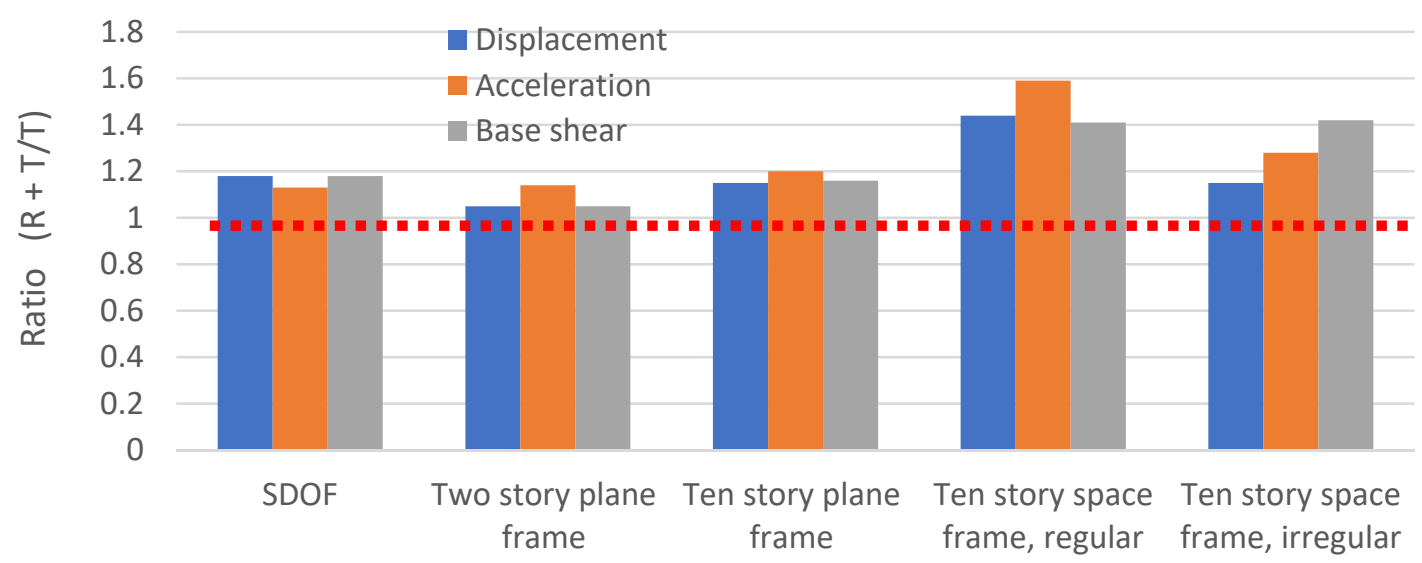

Figure 6. Graphical representation of ratio of response due to translational and rotational component to the response of only translational component, $(T+R) / R$.

\section{Conclusions}

In this work, the effects of rotational components of the earthquake excitation on the response of steel structures was investigated. From the numerical results, it is indicated that the response of structures in terms of displacement, acceleration and base shear, when they are subjected to rotational and translational components is higher than the structural response when subjected to translational component only. For all simulated buildings, the ratio of the response considering the rotational 
component of the excitation over that ignoring ranges from 1.1 to 1.6. With regards to the internal forces, this ratio ranges from 1.3 to 1.85 . Further parametric investigations of different structures with different materials, heights and bay spans need to be done in order to propose a generic value of this ratio. This generic value could be adopted by the design codes and consequently in engineering practice to modify the results obtained from the analysis accounting only for the translational component, to take into account the effects of the rotational components of the excitation.

Author Contributions: Conceptualization, N.P. and F.K.; methodology, N.P.; software, N.P.; validation, F.K., G.P. (Georgios Papavasileiou) and G.P. (George Papagiannopoulos) and G.H.; investigation, all; writing-original draft preparation, all; writing—review and editing, all; visualization, N.P. and F.K.; supervision, N.P. All authors have read and agreed to the published version of the manuscript.

Funding: This research received no external funding.

Conflicts of Interest: The authors declare no conflict of interest.

\section{References}

1. Droste, Z.; Teisseyre, R. Rotational and displacement components of ground motion as deduced from data of the azimuth system of seismographs. Publ. Inst. Geophys. Pol. Acad. Sci. 1976, 97, 157-167.

2. Takeo, M. Rotational motions observed during an earthquake swarm in April 1998 off-shore Ito, Japan. Bull. Seismol. Soc. Am. 2009, 99, 1457-1467. [CrossRef]

3. Igel, H.; Brokesova, J.; Evans, J.; Zembaty, Z. Advances in rotational seismology: Instrumentation, theory, observations, and engineering. J. Seismol. 2012, 16, 571-572. [CrossRef]

4. Liu, C.C.; Huang, B.S.; Lee, W.H.K.; Lin, C.-J. Observing rotational and translational ground motions at the HGSD station in Taiwan from 2007 to 2008. Bull. Seismol. Soc. Am. 2009, 99, 1228-1236. [CrossRef]

5. Wassermann, J.; Lehndorfer, S.; Igel, H.; Schreiber, U. Performance test of a commercial rotational motions sensor. Bull. Seismol. Soc. Am. 2009, 99, 1449-1456. [CrossRef]

6. Lee, V.W.; Trifunac, M.D. Rocking strong earthquake accelerations. Soil Dyn. Earthq. Eng. 1987, 6, 75-89. [CrossRef]

7. Castellani, A.; Boffi, G. On the rotational components of seismic motion. Earthq. Eng. Struct. Dyn. 1989, 18, 785-797. [CrossRef]

8. Li, H.-N.; Sun, L.-Y.; Wang, S.-Y. Improved approach for obtaining rotational components of seismic motion. Nucl Eng. Des. 2004, 232, 131-137. [CrossRef]

9. Basu, D.; Whittaker, A.S.; Constantinou, M.C. On estimating rotational components on ground motion using data recorded at a single station. J. Eng. Mech. ASCE 2012, 138, 1141-1156. [CrossRef]

10. Niazi, M. Inferred displacements, velocities and rotations of a long rigidy site during the 1979 Imperial Valley, California, earthquake. Earthq. Eng. Struct. Dyn. 1986, 14, 531-542. [CrossRef]

11. Spudich, P.; Steck, L.K.; Hellweg, M.; Fletcher, J.B.; Baker, L. Transient stress at Parkfield, California, produced by the M 7.4 Landers earthquake of June 28, 1992: Observations from the UPSAR dense seismograph array. J. Geophys. Res. 1995, 100, 675-690. [CrossRef]

12. Spudich, P.; Fletcher, J.B. Observation and prediction of dynamic ground strains, tilts, and torsions caused by the Mw 6.02004 Parkfield, California, earthquake and aftershocks, derived from UPSAR array observations. Bull. Seismol. Soc. Am. 2008, 98, 1898-1914. [CrossRef]

13. Basu, D.; Whittaker, A.S.; Constantinou, M.C. Extracting rotational components of using data recorded at multiple stations. Earthq. Eng. Struct. Dyn. 2013, 42, 451-468. [CrossRef]

14. Basu, D.; Whittaker, A.S.; Constantinou, M.C. Characterizing rotational components of earthquake ground motion using a surface distribution method and response of sample structures. Eng. Struct. 2015, 99, 685-707. [CrossRef]

15. Falamarz-Sheikhabadi, M.R.; Zerva, A.; Ghafory-Ashtiany, M. Revised Seismic Intensity Parameters for Middle-Field Horizontal and Rocking Strong Ground Motions. J. Struct. Eng. 2016, 143. [CrossRef]

16. Falamarz-Sheikhabadi, M.R. Simplified relations for the application of rotational components to seismic design codes. Eng. Struct. 2014, 59, 141-152. [CrossRef] 
17. Sbaa, S.; Hollender, F.; Perron, V.; Imtiaz, A.; Bard, P.; Mariscal, A.; Cochard, A.; Dujardin, A. Analysis of rotation sensor data from the SINAPS@ Kefalonia (Greece) post-seismic experiment-Link to surface geology and wavefield characteristics. Earth Planets Space 2017, 69, 124. [CrossRef]

18. Perron, V.; Hollender, F.; Mariscal, A.; Theodoulidis, N.; Andreou, C.; Bard, P.; Cornou, C.; Cottereau, R.; Cushing, E.M.; Frau, A.; et al. Accelerometer, Velocimeter Dense-Array, and Rotation Sensor Datasets from the Sinaps@ Postseismic Survey (Cephalonia 2014-2015 Aftershock Sequence). Seismol. Res. Lett. 2018, 89, 678-687. [CrossRef]

19. EN 1998-6. Eurocode 8: Design of Structures for Earthquake Resistance-Part 6: Towers, Masts and Chimneys; Brussels, Belgium. 2005.

20. Wolf, J.P.; Obernhueber, P.; Weber, B. Response of a nuclear plant on aseismic bearings to horizontally propagating waves. Earthq. Eng. Struct. Dyn. 1983, 11, 483-499. [CrossRef]

21. Politopoulos, I. Response of seismically isolated structures to rocking-type actions. Earthq. Eng. Struct. Dyn. 2010, 39, 325-342.

22. Bonev, Z.; Blagov, D.; Vaseva, E.; Mladenov, K. Accounting the rotational component of Seismic action on towers, masts and chimneys according to BDS EN 1998-6. International conference UACG-2009: Science and Practice. Fascicule VIII 2009, XLIV, 185-195.

23. Zembaty, Z. Rotational seismic code definition in Eurocode 8, Part 6, for slender tower-shaped structures. Bull. Seismol. Soc. Am. 2009, 99, 1483-1485. [CrossRef]

24. Zembatyy, Z.; Boffi, G. Effect of rotational seismic ground motion on dynamic response of slender towers. Eur. Earthq. Eng. 1994, 8, 3-11.

25. Zembaty, Z.; Mutke, G.; Nawrocki, D.; Bobra, P. Rotational ground-motion records from induced seismic events. Seismol. Res. Lett. 2017, 88, 13-22. [CrossRef]

26. Falamarz-Sheikhabadi, M.R.; Ghafory-Ashtiany, M. Rotational components in structural loading. Soil Dyn. Earthq. Eng. 2015, 75, 220-233. [CrossRef]

27. Falamarz-Sheikhabadi, M.R.; Zerva, A.; Ghafory-Ashtiany, M. Mean absolute input energy for in-plane vibrations of multiple-support structures subjected to horizontal and rocking components. J. Probab. Eng. Mech. 2016, 45, 87. [CrossRef]

28. Basu, D.; Constantinou, M.C.; Whittaker, A.S. An equivalent accidental eccentricity to account for the effects of torsional ground motion on structures. Eng. Struct. 2014, 69, 1-11. [CrossRef]

29. De-La-Llera, J.C.; Chopra, A.K. Accidental torsion in buildings due to base rotational excitation. Earthq. Eng. Struct. Dyn. 1994, 23, 1003-1021. [CrossRef]

30. Yin, J.; Nigbor, R.L.; Chen, Q.; Steidl, J. Engineering analysis of measured rotational ground motions at GVDA. Soil Dyn. Earthq. Eng. 2016, 87, 125-137. [CrossRef]

31. Pnevmatikos, N.G.; Papavasileiou, G.S.; Konstandakopoulou, F.D.; Papagiannopoulos, G.A. Influence of Rotational Component of Earthquake Excitation to the Response of Steel Slender Frame. In Materials Science Forum; Trans Tech Publications Ltd.: Freienbach, Switzerland, 2019; Volume 968, pp. 294-300.

32. Pnevmatikos, N.G.; Papavasileiou, G.S.; Konstandakopoulou, F.D.; Papagiannopoulos, G.A. Analysis of a steel structure considering the rotational and translational components of the earthquake excitation. In Proceedings of the 4th Hellenic National Conference on Earthquake Engineering and Technical Seismology, Athens, Greece, 5-7 September 2019.

33. Chopra, A. Dynamics of structures. In Theory and Application to Earthquake Engineering, 3rd ed.; Pearson Prentice Hall: Bergen, NJ, USA, 2007.

34. SAP2000, Computers and Structures, Inc. Linear and Nonlinear, Static and Dynamic Analysis and Design of Three-Dimensional Structures; Computers and Structures, Inc.: Berkeley, CA, USA, 2011.

(C) 2020 by the authors. Licensee MDPI, Basel, Switzerland. This article is an open access article distributed under the terms and conditions of the Creative Commons Attribution (CC BY) license (http://creativecommons.org/licenses/by/4.0/). 